\title{
EFFECTS OF BACKFILL SOIL ON PIPELINE'S MECHANICAL RESPONSE SUBJECTED TO PERILOUS ROCK IMPACT
}

\author{
Jie Zhang ${ }^{1,2^{*}}$ - Wei Guo - Haiyang Li $^{2}$ \\ ${ }^{1}$ Key Laboratory of Safe and Effective Coal Mining (Anhui University of Science and Technology), Ministry of \\ Education, Huainan, China \\ ${ }^{2}$ School of Mechatronic Engineering, Southwest Petroleum University, Chengdu, China
}

\begin{tabular}{l} 
ARTICLE INFO \\
\hline Article history: \\
Received: 27.7 .2017$. \\
Received in revised form: 2.3 .2018$. \\
Accepted: 12.3 .2018$. \\
\hline Keywords: \\
buried pipeline \\
backfill soil \\
perilous rock \\
mechanical property \\
plastic strain \\
impact dent \\
\hline DOI: http://doi.org/10.30765/er.40.1.04
\end{tabular}

\section{Introduction}

Collapse is one of the most serious geological disasters that threats to buried pipeline security under poor geological conditions. The main hazard of collapse is the perilous rock that falls off mountain or slope. For example, perilous rock hazard is one of the most serious geological disasters to threat to the security of Zhong-Wu gas pipeline. In 2005, pipeline concrete cover plate was punctured by a perilous rock with $350 \mathrm{~m}^{3}$ in Shunxi. And a dent with $30 \mathrm{~cm}$ in diameter appeared in the pipeline [1]. A number of perilous rock impact pipeline events have occurred in Lan-Cheng-Yu

\footnotetext{
* Corresponding author. Tel.: +86-02883037209

E-mail address: longmenshao@163.com
}

\begin{abstract}
:
Perilous rock impact is one of the most serious geological disasters that threats to buried pipeline security. Mechanical behavior of buried pipeline in rock stratum impacted by perilous rock was investigated. Effects of impact velocity and backfill soil parameters on stress and strain of pipeline were discussed. The results show that cross section shape of pipeline is oval before a dent appears. Impact dent appears on pipeline with the increasing of impact velocity, buckling is more serious and plastic stain increases. Under low velocity impact, stress and plastic strain decrease with the increasing of soil's elastic modulus. Plastic strain increases first and then decreases with the increasing of soil's Poisson's ratio. With the increasing of soil's cohesion, plastic strain increases, but stress first increases and then decreases. Under high velocity impact, deformation and plastic strain increase with the decreasing of elastic modulus and Poisson's ratio. But soil cohesion has a small effect on buckling behavior of pipeline.
\end{abstract}

Pipeline [2], which have threatened the safe operation of oil and gas pipeline seriously. Under perilous rock impact, buried pipelines may rupture, then causing medium leakage. Or pipeline anticorrosion layer was damaged, scratches and dents appear. If leak accidents occur, it may cause fire, explosion, poisoning, and environment pollution.

Research on mechanical property of buried pipeline under perilous rock impact is very important to pipeline operation. Li et al. [3] analyzed the stress and strain of buried pipeline from impact load. Wang et al. [4] simulated the perilous rock movement by rock-fall software, and impact load of buried pipeline was evaluated with two methods. 
Deng et al. [5] simulated the dynamic response of buried pipeline induced by rock-fall impaction by 3DEC software. Xiong et al [6] studied the influence law of certain factors on the safety of buried pipeline by the explicit dynamic analysis software LS-DYNA. These researches are mainly focused on the stress and strain of buried pipeline when the impact load is very small, but not considering the buckling behavior. For buried pipeline, backfill soil is the mediation between perilous rock and pipeline, and it has a great effect on the mechanical property of buried pipeline [7].

Strata mostly is hard rock in the mountain area. Therefore, mechanical behavior of buried pipeline in rock stratum impacted by perilous rock was simulated in this paper. Stress and plastic strain of buried pipeline under different impact velocities were studied. That will provide a basis of pipeline laying and protection engineering in bad geological region.

\section{Materials and methods}

If buckling appears on the pipeline after impacted by perilous rock, it is different to calculate deformation by the theoretical formula. Soilpipeline interaction is an important factor for the buckling behavior. In addition, pipeline is a thin shell structure, superposition principle is not used for the interaction of stress and strain [8]. Finite element method is more suitable to analyze the buckling of buried pipeline impacted by perilous rock. Impact problem of buried pipeline has been studied using a finite element model, considering geometrical and material nonlinearities.

This paper assumes the shape of perilous rock as a cube. Fig. 1 shows the finite element models of buried pipeline, perilous rock and stratum. The pipeline is embedded in and elongated soil prism along $\mathrm{Z}$ axis. Shell element is employed to mesh pipeline, and hexahedral element is used to simulate the backfill soil and stratum. Diameter of the pipeline is $813 \mathrm{~mm}$, wall thickness of the pipeline is $8 \mathrm{~mm}$, and perilous rock's size is $1.4 \mathrm{~m} \times 1.4 \mathrm{~m} \times 1.4 \mathrm{~m}$. In order to eliminate the edge effect, size of the stratum is $10 \mathrm{~m} \times 7.5 \mathrm{~m} \times 15 \mathrm{~m}$. The thickness of overlying soil is $1 \mathrm{~m}$. A penalty contact algorithm is employed to simulate the interaction of surfaces of buried pipeline and backfill soil, and the friction coefficient is 0.3 . The bottom surface of stratum is fixed.
A large-strain plasticity model with isotropic hardening is employed for the steel pipeline material. Numerical results are obtained for X65 steel pipeline. Yield stress is 448.5MPa, Young's modulus is $206 \mathrm{GPa}$, Poisson's ratio is 0.3 , and density is $7800 \mathrm{~kg} / \mathrm{m}^{3}$. Mechanical behaviors of soil and rock material are described through an elasticperfectly plastic Mohr-Coulomb constitutive model. Materials of rock stratum and perilous rock are the same. The backfill soil's cohesion is $15 \mathrm{kPa}$, friction angle is $15^{\circ}$, elastic modulus is $20 \mathrm{MPa}$, density is $1840 \mathrm{~kg} / \mathrm{m}^{3}$, and Poisson's ratio is 0.3 . The rock is limestone, its cohesion is $6.72 \mathrm{MPa}$, friction angle is $42^{\circ}$, elastic modulus is $28.5 \mathrm{GPa}$, density is $2090 \mathrm{~kg} / \mathrm{m}^{3}$, and Poisson's ratio is 0.29 .

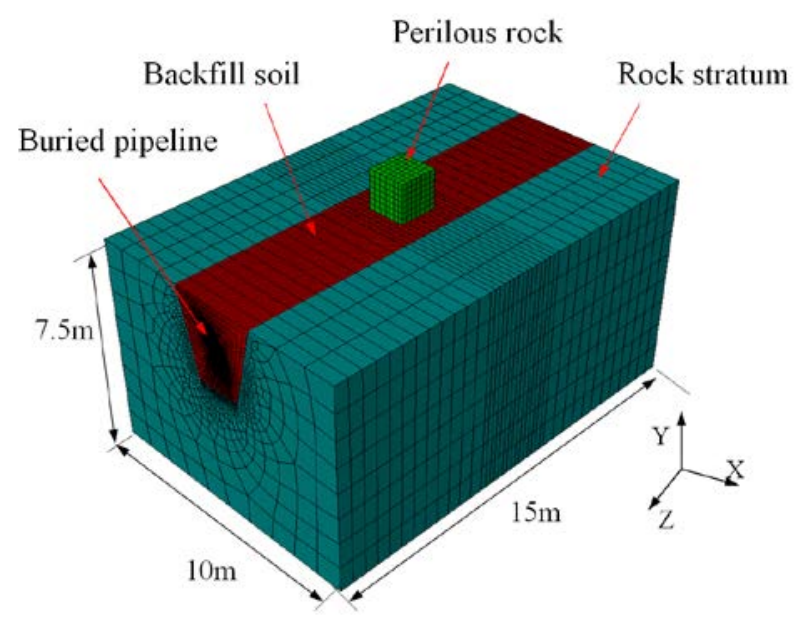

Figure 1. Finite element models

\section{Simulations results}

Figure 2 shows the deformation process of buried pipeline impacted by perilous rock. The pipeline deformation process can be divided into three stages.

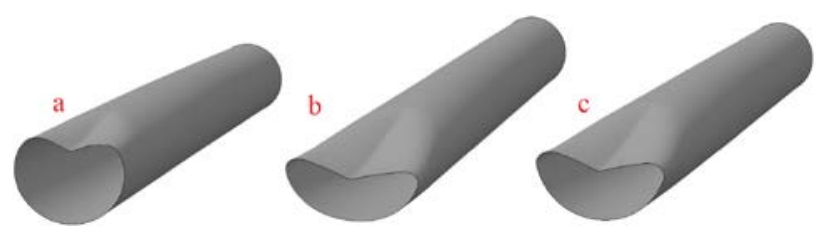

Figure 2. Deformation process of the buried pipeline

The first stage is initial deformation (as shown in Fig. 2(a)), perilous rock intrudes into backfill soil and the soil is compressed, then a dent appears on the pipeline. The second stage is the maximum 
deformation (as shown in Fig. 2(b)), velocity of perilous rock becomes zero under the backfill soil resistance. The third stage is final deformation (as shown in Fig. 2(c)), impact load disappears in this stage. Elastic deformation caused by impact load returns. But the elastic deformations caused by gravity of backfill soil and perilous rock are still existing.

Figure 3. shows von Mises stress of buried pipeline under different impact velocities. When $v=10 \mathrm{~m} / \mathrm{s}$, the maximum stress appears on the lower part of buried pipeline. But with the impact velocity increases, stress of the upper part of the pipeline is bigger than the lower part. Buckling occurs when $v=20 \mathrm{~m} / \mathrm{s}$, high stress ring is formed. The maximum stress isn't on impact location of the pipeline. Dent with a ship shape appears with the impact velocity increases, and there are five high stress zones.

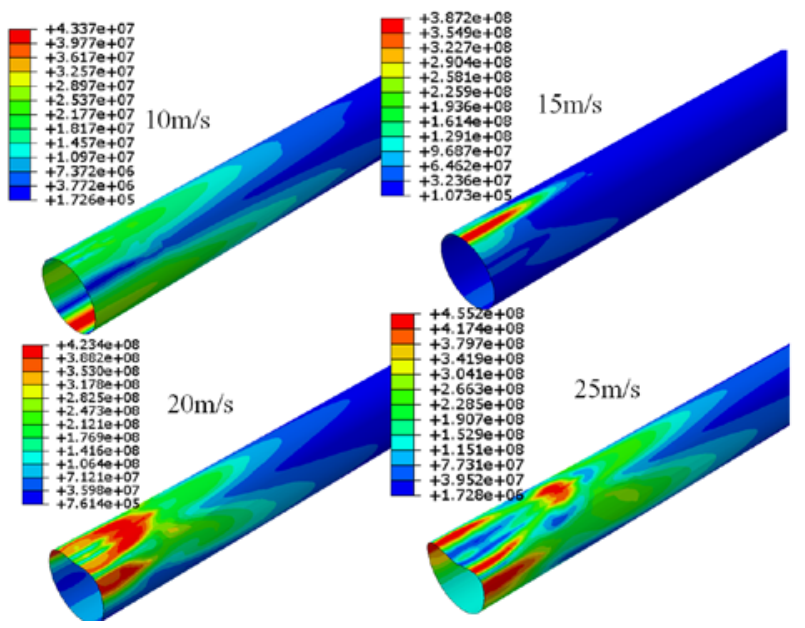

Figure 3. Von Mises stress under different impact velocities

Cross section deformations of buried pipeline under different impact velocities are shown in Fig. 4. When $v \leq 15 \mathrm{~m} / \mathrm{s}$, there is no buckling, and the cross section shape is oval. The bigger impact velocity is, the greater ovality $\left(k=\left(D_{\max }-D_{\min }\right) / D \times 100 \%\right)$ of buried pipeline is. With the increasing of impact velocity, pipeline instability and buckling appear. Cross section of buried pipeline becomes to peach shape, and impact dent occurs. Buckling is more serious with the increasing of impact velocity, and impact dent is bigger.

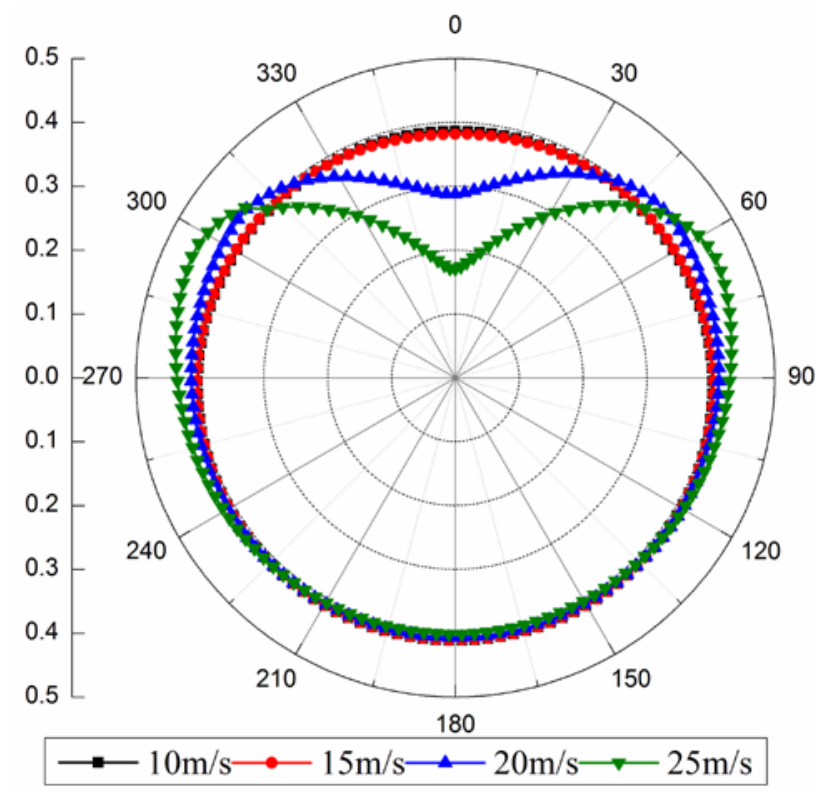

Figure 4. Deformation of pipeline under different impact velocities

\section{Backfill soil property}

\subsection{Elasticity modulus effect}

When $v=15 \mathrm{~m} / \mathrm{s}$, the maximum von Mises stress and plastic strain under different elastic modulus of backfill soil are shown in Fig. 5.

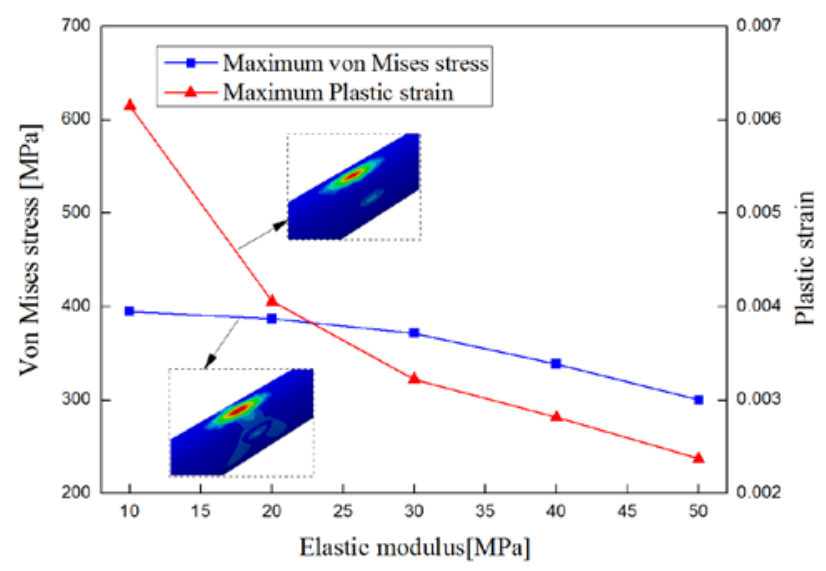

Figure 5. Stress and strain of the pipeline

The high stress zone and plastic strain zone of buried pipeline is oval under low velocity impact. With the increasing of elastic modulus of backfill soil, the maximum von Mises stress and plastic strain decrease. Although the maximum von Mises stress is smaller than yield limit when the elastic modulus of backfill soil is bigger, plastic strain is 
still exist. Because the perilous rock impact process is dynamic. Plastic strain appears when the impact velocity of perilous rock decreases to zero, but the elastic deformation will be restored later and the stress also decreases in final state. As shown in Table 1, ovality of buried pipeline decreases with the increasing of elastic modulus of backfill soil. Therefore, deformation of buried pipeline under backfill soil with a low elastic modulus is serious when impacted by perilous rock.

Table 1 Ovality of pipeline under different parameters of backfill soil

\begin{tabular}{|c|c|c|c|c|c|}
\hline$E / \mathrm{MPa}$ & $k / \%$ & $v$ & $k / \%$ & $\underline{c} / \mathrm{kPa}$ & $k / \%$ \\
\hline 10 & 2.76 & 0.20 & 1.94 & 10 & 1.35 \\
\hline 20 & 1.96 & 0.25 & 2.06 & 15 & 1.96 \\
\hline 30 & 1.67 & 0.30 & 1.96 & 20 & 2.10 \\
\hline 40 & 1.48 & 0.35 & 1.86 & 25 & 1.90 \\
\hline 50 & 1.43 & 0.40 & 1.57 & 30 & 1.95 \\
\hline- & - & - & - & 35 & 2.29 \\
\hline- & - & - & - & 40 & 2.74 \\
\hline
\end{tabular}

When $v=25 \mathrm{~m} / \mathrm{s}$, deformation of buried pipeline in $\mathrm{XY}$ and YZ plane under different elastic modulus of backfill soil are shown in Fig. 6. Buckling appears on the buried pipeline in this condition, and it is more serious with the decreasing of elastic modulus of backfill soil. As shown in Fig. 6(b), impact dent of buried pipeline is bigger under backfill soil with a smaller elastic modulus. The impact dent depth decrease with the increasing of elastic modulus, and the change rate also decreases.

Figure 7 shows the plastic strain of buried pipeline under different elastic modulus of backfill soil when $v=25 \mathrm{~m} / \mathrm{s}$. Plastic strain distributions of buried pipeline are similar under different elastic modulus. But when $E=10 \mathrm{MPa}$, the bigger plastic strain zones are in the middle ling and two sides of the impact dent. When $E>10 \mathrm{MPa}$, there is only one bigger plastic strain zone. Plastic strain increases with the decreasing of elastic modulus of backfill soil.

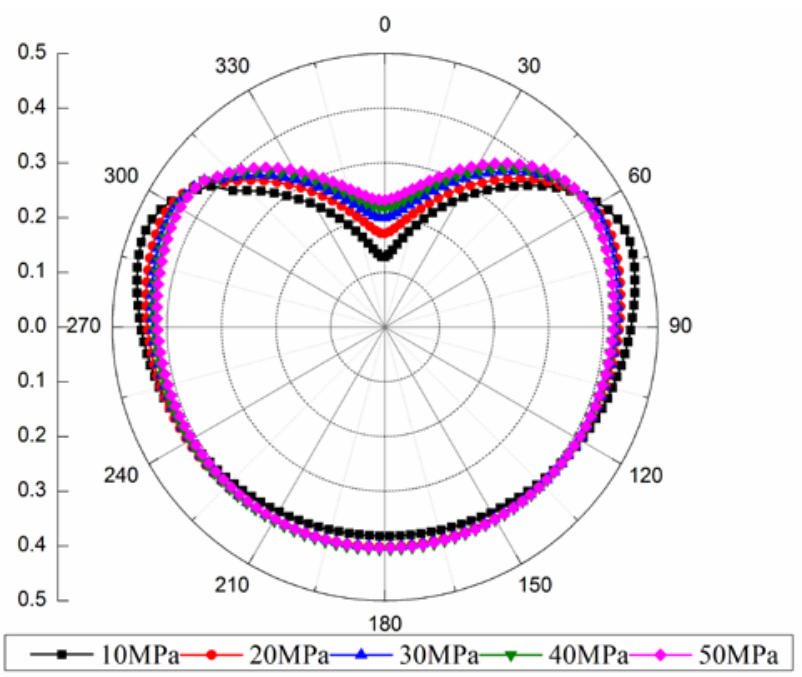

(a) XY plane

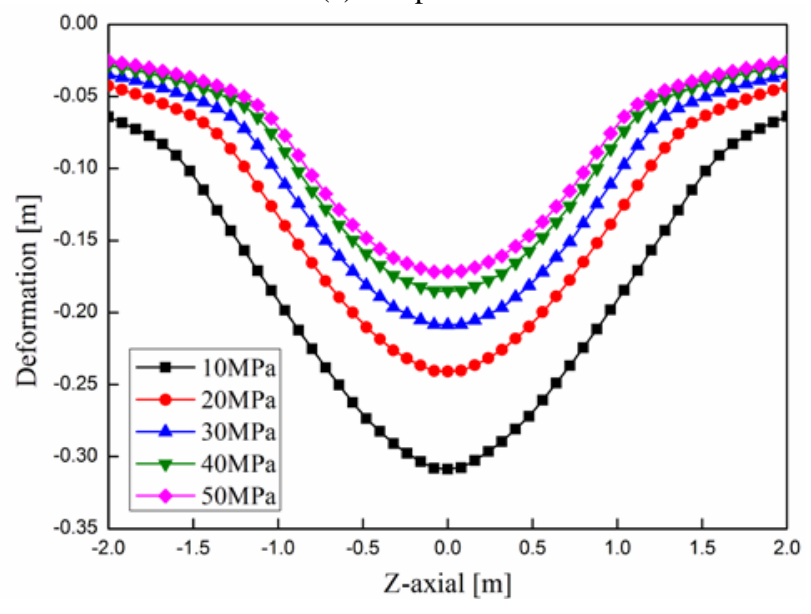

(b) YZ plane

Figure 6. Deformation of buried pipeline under different elastic modulus when $v=25 \mathrm{~m} / \mathrm{s}$

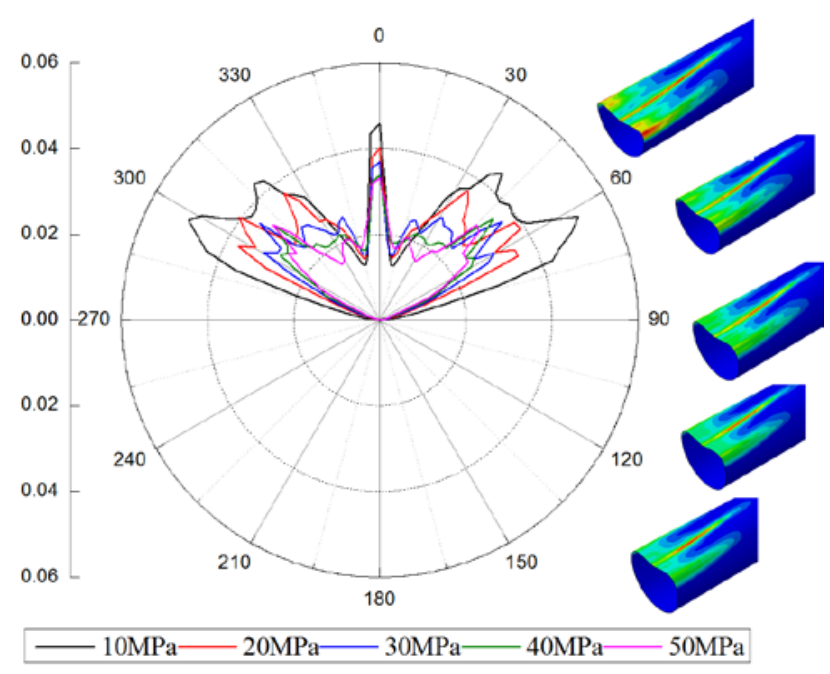

Figure 7. Plastic strain of buried pipeline under different elastic modulus when $v=25 \mathrm{~m} / \mathrm{s}$ 


\subsection{Poisson's ratio effect}

When $v=15 \mathrm{~m} / \mathrm{s}$, the maximum von Mises stress and plastic strain under different Poisson's ratios of backfill soil are shown in Fig. 8. With the increasing of Poisson's ratio of backfill soil, the maximum von Mises stress of buried pipeline decreases. But maximum plastic strain first increases and then decreases. When $v=0.4$, von Mises stress and plastic strain of buried pipeline are very small. As shown in Table 1, with the increasing of Poisson's ratio of backfill soil, ovality of buried pipeline first increases and then decreases. Therefore, deformation of buried pipeline under backfill soil with $v=0.25$ is the biggest after impacted by perilous rock.

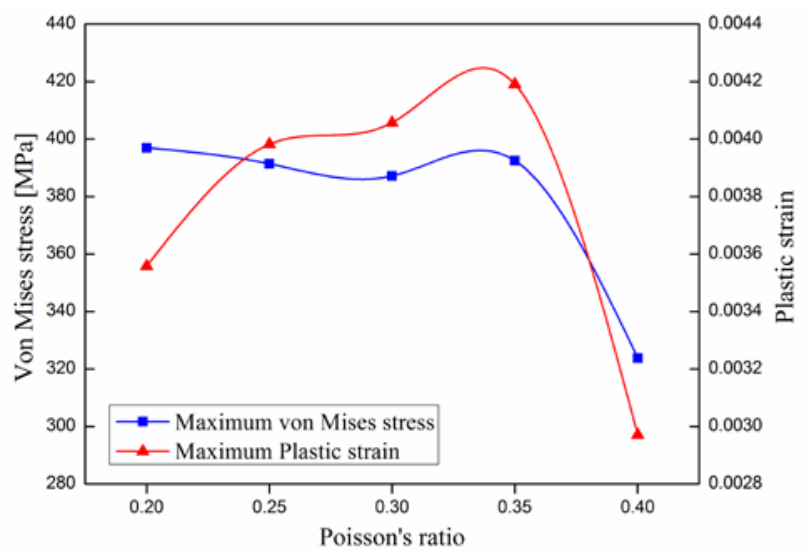

Figure 8. Maximum stress and plastic strain under different Poisson's ratios when $v=15 \mathrm{~m} / \mathrm{s}$

When $v=25 \mathrm{~m} / \mathrm{s}$, deformation of buried pipeline in $\mathrm{XY}$ and YZ plane under different Poisson's ratios of backfill soil are shown in Fig. 9. Buckling of buried pipeline is more serious with the decreasing of Poisson's ratio of backfill soil. As shown in Fig. 9(b), impact dent depth change is uniform when $v \leq 0.35$, and change rate is small. But when $v=0.4$, impact dent depth is smaller.

Fig. 10 shows the plastic strain of buried pipeline under different Poisson's ratios of backfill soil when $v=25 \mathrm{~m} / \mathrm{s}$. Plastic strain distributions of buried pipeline are similar under different Poisson's ratios. Plastic strain of buried pipeline decreases with the increasing of Poisson's ratio of backfill soil.

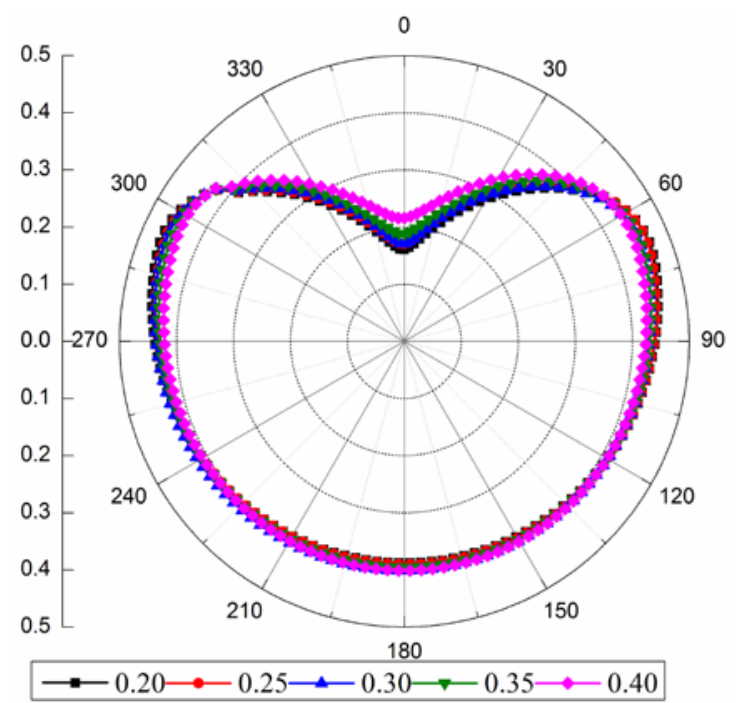

(a) XY plane

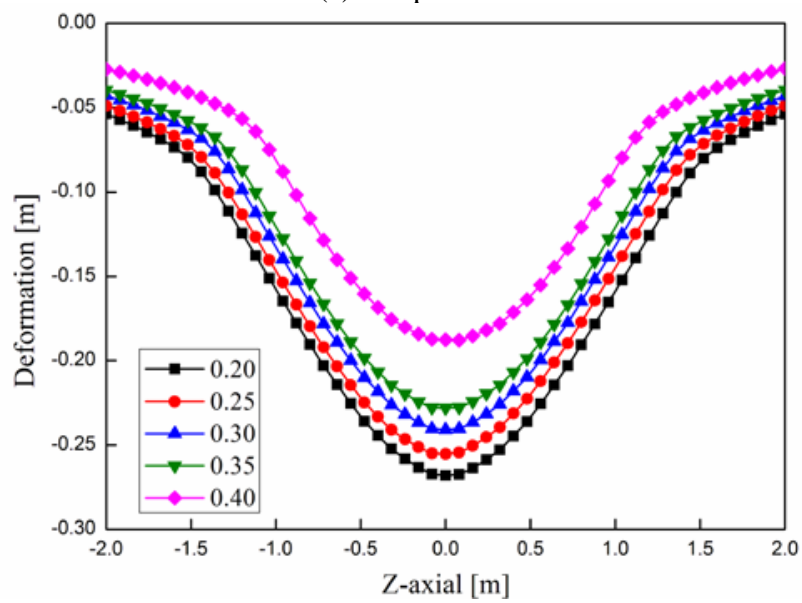

(b) YZ plane

Figure 9. Deformation of buried pipeline under different Poisson's ratios when $v=25 \mathrm{~m} / \mathrm{s}$

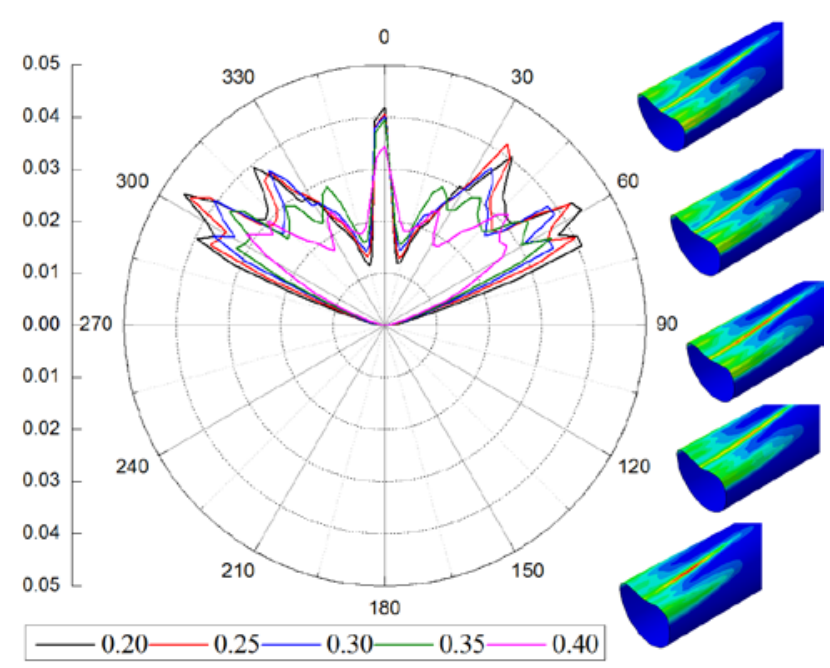

Figure 10. Plastic strain under different Poisson's ratios 


\subsection{Cohesion effect}

When $v=15 \mathrm{~m} / \mathrm{s}$, the maximum von Mises stress and plastic strain under different cohesions of backfill soil are shown in Fig. 11. With the increasing of cohesion of backfill soil, the maximum plastic strain of buried pipeline increases. But maximum von Mises stress first increases and then decreases. When $c=25 \mathrm{kPa}$, von Mises stress of buried pipeline is biggest. As shown in Table 1, with the increasing of cohesion of backfill soil, there is a fluctuation of pipeline ovality. So, deformation of buried pipeline has a bigger nonlinear with the cohesion of backfill soil when impacted by perilous rock.

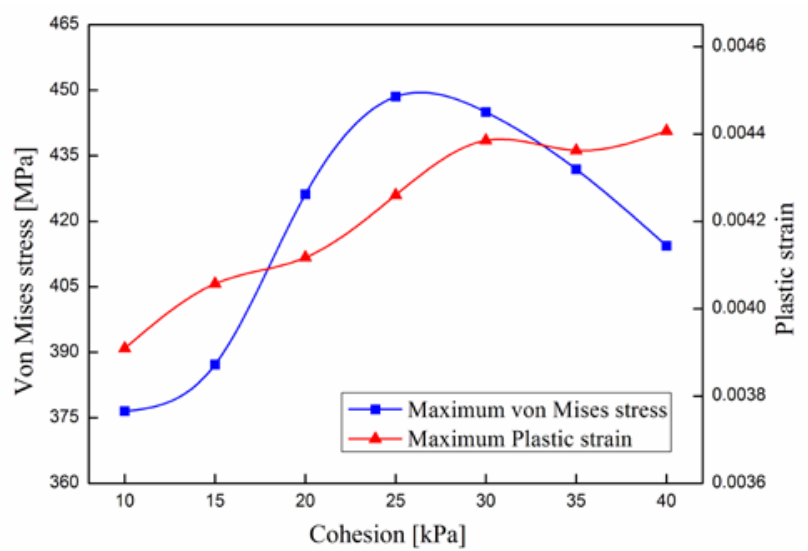

Figure 11. Stress and strain under different cohesions

When $v=25 \mathrm{~m} / \mathrm{s}$, deformation of buried pipeline in $\mathrm{XY}$ and YZ plane under different cohesions of backfill soil are shown in Fig. 12. Cohesion of backfill soil has a small effect on buckling of buried pipeline under high velocity impact. Fig. 13 shows the plastic strain of buried pipeline under different cohesions of backfill soil when $v=25 \mathrm{~m} / \mathrm{s}$. Plastic strain of buried pipeline are similar under different cohesions. Therefore, deformation and strain of buried pipeline are less affected by cohesion of backfill soil under high velocity impact.

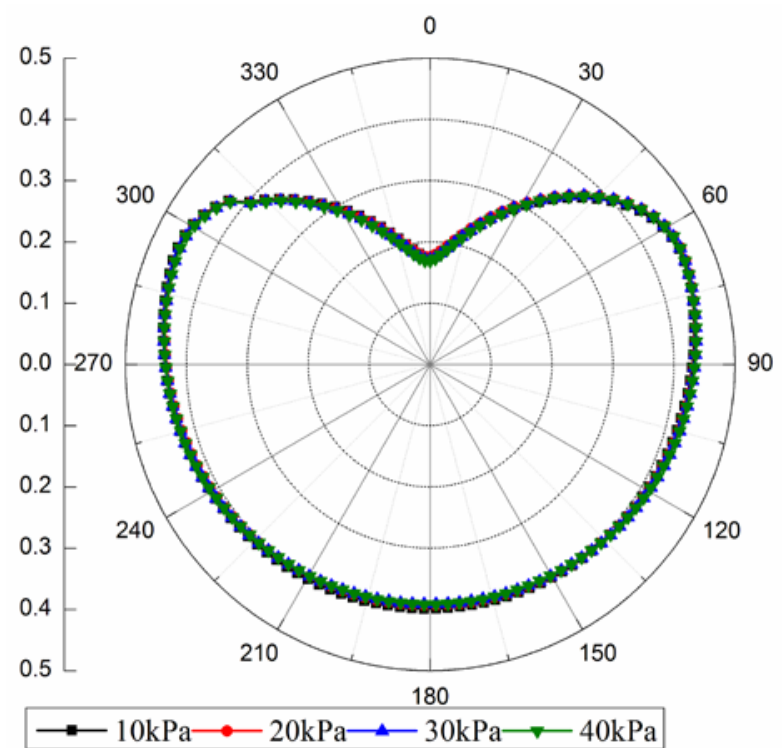

(a) XY plane

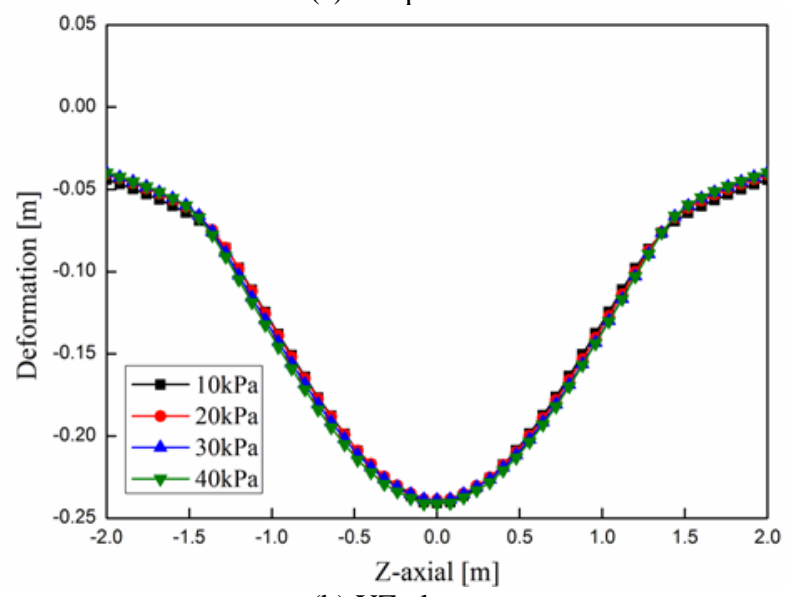

(b) YZ plane

Figure 12. Deformation of buried pipeline under different cohesions when $v=25 \mathrm{~m} / \mathrm{s}$

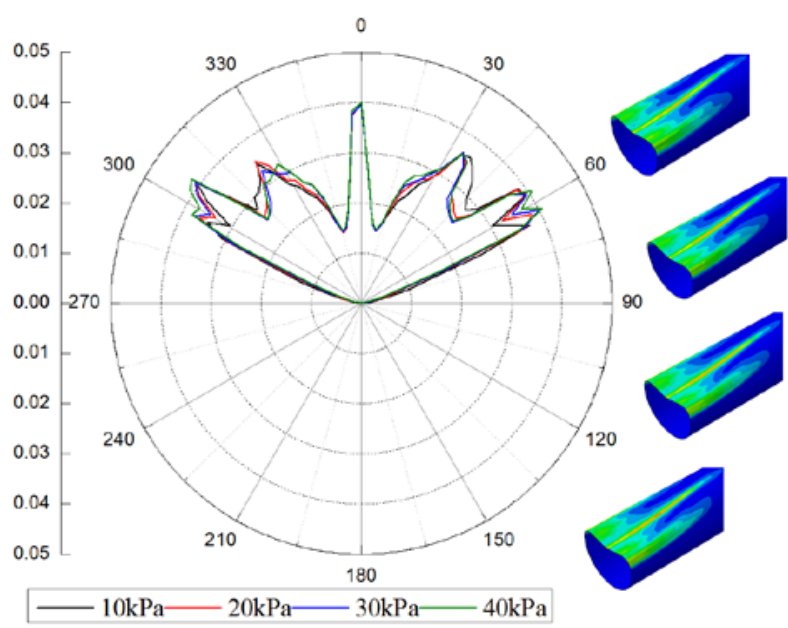

Figure 13. Plastic strain of buried pipeline under different cohesions when $v=25 \mathrm{~m} / \mathrm{s}$ 


\section{Conclusions}

(1) Under the same volume of perilous rock, a dent with ship shape appears on the buried pipeline with the increasing of impact velocity. Buckling is more serious and plastic stain increases.

(2) When impact velocity is $15 \mathrm{~m} / \mathrm{s}$, high stress zone and plastic strain zones of buried pipeline are oval. Von Mises stress, plastic strain and ovality decrease with the increasing of elastic modulus of backfill soil. With the increasing of Poisson's ratio of backfill soil, plastic strain and ovality first increase and then decrease. With the increasing of cohesion of backfill soil, plastic strain increases, but von Mises stress first increases and then decreases.

(3) When the impact velocity is $25 \mathrm{~m} / \mathrm{s}$, buckling is more serious with the decreasing of elastic modulus and Poisson's ratio of backfill soil. Plastic strain increases with the decreasing of elastic modulus and Poisson's ratio of backfill soil. Cohesion of backfill soil has a small effect on buckling of buried pipeline.

\section{Acknowledgements}

This paper is supported by Sichuan Science and Technology Plan (2019123, 2019YJ0319), Chengdu International Cooperation Project (2019-GH0200072-HZ), China Postdoctoral Science Foundation (2019M653839XB), Youth Research and Innovation Team of SWPU (2018CXTD12).

\section{References}

[1] Wang L.: Dynamic response of shallow buried gas pipeline caused by dangerous rock fall impaction, West-China Exploration Engineering, 25 (2013), 2, 13-17.

[2] Shi X. W., Deng Q. L., Dong G. L.: The hazards of landslides and rockslides to pipeline, Oil and Gas Storage and Transportation, 32 (2013), 3, 295-299.

[3] Li Y. B., Wang J. H., Zhang G. T., Ma W. X.: Analysis of the buried pipeline stress and deformation due to the impact load of landslide, Journal of Logistical Engineering University, 26 (2010), 6, 31-35.

[4] Wang, L., Deng, Q. L., Yang, H. J., Jing, H. Y.: Evaluation on the safety of natural gas pipeline impacted by dangerous rock fall, Hydrogeology \& Engineering Geology, 51 (2007), 5, 29-32.

[5] Deng, X. J., Xue, S. F., Tong, X. H.: Numerical simulation in response of buried pipeline induced by rock-fall transverse impaction, Journal of China University of Petroleum, 23 (2009), 6, 111-115.

[6] Xiong J., Deng, Q. L., Zhang, H. L., Pang, W. J.: Safety assessment on the response of buried pipeline caused by rockfall impact load, Safety and Environmental Engineering, 20 (2013), 1, 108-114.

[7] Zhang, J., Zhang, L., Liang, Z.: Buckling failure of a buried pipeline subjected to ground explosions, Process Safety and Environmental Protection, 114 (2018),36-47.

[8] Zhang, J., Xie R.: Numerical analysis of mechanical behavior of buried pipes in subsidence area caused by underground mining, Journal of Pressure Vessel Technology, 141 (2019), 021703. 